\title{
Erratum to: Photodynamic Therapy for Unresectable Cholangiocarcinoma
}

\author{
Yutaka Tomizawa $\cdot$ Jianmin Tian
}

Published online: 17 March 2012

(C) Springer Science+Business Media, LLC 2012

Erratum to: Dig Dis Sci (2012) 57:274-283

DOI 10.1007/s10620-011-1957-7

Description of errors and corrections:

1. Correction: page 280 line 17: reference numbers [30, $35,36]$.

2. Correction: page 280 line 23: survival rates of $78 \%$ and $39 \%$, respectively.

3. Correction: page 281 line 48: survival after PDT for CC [31].

4. Correction: Table 1, Table 2, Table 3, Table 4: authors' names and reference numbers are these below in order (authors [reference number]):

Ortner et al. [35]

Berr et al. [36]

Rumalla et al. [30]
Zoepf et al. [28]

Zoepf et al. [29]

Wiedmann et al. [48]

Dumoulin et al. [38]

Ortner et al. [43]

Wiedmann et al. [39]

Nanashima et al. [47]

Harewood et al. [37]

Shim et al. [42]

Zoepf et al. [45]

Witzigmann et al. [41]

Prasad et al. [31]

Kahaleh et al. [46]

Fuks et al. [40]

Contact me for a revised version if necessary

The online version of the original article can be found under doi:10.1007/s10620-011-1957-7.

Y. Tomizawa $(\bowtie)$

Department of Medicine, University of Pittsburgh Medical Center, 5230 Center Avenue, Pittsburgh, PA 15232, USA

e-mail: tomizaway@upmc.edu

J. Tian

Division of Gastroenterology and Hepatology, Mayo Clinic,

200 1st Street SW, Rochester, MN 55905, USA

e-mail: Tian.Jianmin@mayo.edu 